\title{
Outcomes study between femtosecond laser- assisted cataract surgery and conventional phacoemulsification surgery using an active fluidics system
}

\author{
This article was published in the following Dove Press journal: \\ Clinical Ophthalmology \\ 25 September 2017 \\ Number of times this article has been viewed
}

\author{
Wilson Takashi Hida ${ }^{1-4}$ \\ Patrick Frenzel Tzelikis ${ }^{1-3}$ \\ César Vilar ${ }^{1,2}$ \\ Mario Augusto Pereira Dias \\ Chaves ${ }^{1,2,5}$ \\ Antônio Francisco Pimenta \\ Motta $^{1-3}$ \\ Pedro Carlos Carricondo ${ }^{1-3}$ \\ Bruna Vieira Ventura ${ }^{1,2,4,6}$ \\ Renato Ambrosio Junior ${ }^{1-3}$ \\ Walton Nosé $1,2,4$ \\ Milton Ruiz Alves ${ }^{1-3}$ \\ 'Department of Cataract of Brasília \\ Ophthalmology Hospital (HOB), \\ Brasília, Federal District, ${ }^{2}$ Renato \\ Ambrosio Research Center (CEORA), \\ Brasília, Federal District, ${ }^{3}$ Department \\ of Ophthalmology of São Paulo \\ University School of Medicine, \\ (FM-USP), São Paulo, ${ }^{4}$ Department \\ of Ophthalmology of São Paulo \\ Federal University (UNIFESP) School \\ of Medicine, São Paulo, ${ }^{5}$ ProVisão \\ Hospital, João Pessoa, Paraíba, \\ ${ }^{6}$ Pernanbuco Eye Hospital (HOPE), \\ Recife, Pernambuco, Brazil
}

Purpose: The purpose of this study was to compare intraoperative parameters between femtosecond laser-assisted cataract surgery (FLACS) and conventional phacoemulsification using Centurion ${ }^{\circledR}$ Vision System with Active Fluidics.

Setting: This study was performed at Brasília Ophthalmologic Hospital, Brasília, Federal District, Brazil.

Patients and methods: This was a prospective randomized comparative study. Patients with the diagnosis of cataract and surgical extraction programmed were divided into two groups: conventional phacoemulsification and FLACS. Intraoperative data were collected and submitted for statistical analysis.

Results: A total of 400 eyes were enrolled, 200 in each group. There were no surgical complications. Groups were statistically equivalent in age and nucleus density. Cumulative dissipated energy and torsional time were significantly reduced in the FLACS group. Conventional surgery had less fluid usage, total case time and aspiration (ASP) time.

Conclusion: FLACS with Active Fluidics System can reduce the ultrasound energy use during cataract surgery, in spite of increasing case time, fluid usage and ASP time.

Keywords: FLACS, ultrasound, aspiration

\section{Introduction}

Cataract surgery is the most common surgical procedure performed worldwide. Its frequency has greatly increased in the past few decades due to aging of the population and augmented visual needs along with technology development. ${ }^{1}$

Phacoemulsification made possible for the surgeon to achieve superior and predictable visual outcomes. It consists of an oscillating tip to emulsify the lens associated with an irrigation and aspiration (ASP) device. As incisions developed much smaller and faster healing and foldable intraocular lenses became available, it turned into the preferred technique for cataract removal worldwide. Generation after generation, phacoemulsification machines provided better surgical performance and improved safety. Intraocular use of ultrasound is a major concern for surgeons, since if used recklessly may damage near structures, including corneal endothelium., ${ }^{2,3}$

Recently, the Centurion ${ }^{\circledR}$ Vision System (Alcon Laboratories, Inc., Fort Worth, TX, USA) introduced Active Fluidics ${ }^{\mathrm{TM}}$ platform, which has shown better stability of anterior chamber, decreasing the postocclusion surge even at high ASP and vacuum
Correspondence: Wilson Takashi Hida SHIS QI 5 Conjunto 8 Casa 4, Lago Sul, Brasilia, Federal District 71615-080, Brazil,

Email takashi.doc@gmail.com 
settings with lower intraocular pressure during the procedure, compared with other platforms. ${ }^{4,5}$

Femtosecond laser-assisted cataract surgery (FLACS) is the latest major change in surgical technique since the introduction of phacoemulsification. It has been increasingly adopted in cataract surgery centers. This technology consists of a photodissection laser to create corneal incisions, anterior capsulotomy and fragmentation of the nucleus, which are key steps of the cataract surgery. The remaining steps (ASP of the lens cortical material and implantation of the lens) of the surgery still need an assessment of surgeons' ability to complete the surgery. According to the recently published evidence, the laser is more accurate in executing the capsulorrhexis (shape and size), achieving better centration of the intraocular lens and fewer tilt and intraocular high-order aberrations. ${ }^{6-9}$ The previous fragmentation of the nucleus also allows for less use of ultrasound energy, reducing risk of structural damage. ${ }^{7,8,10-13}$

Since the new technique is of substantial cost, many papers have addressed to compare conventional surgery versus FLACS; however, there is still lack of evidence to describe whether the new technique actually brings effective phacoemulsification time. ${ }^{21}$ In addition, there is great bias involving surgeons still in learning curve of the technique and studies comprising different surgeons and phaco machines. ${ }^{7,9-13}$

This study aimed to compare clinical and intraoperative parameters between FLACS versus conventional phacoemulsification using Centurion Vision System with Active Fluidics.

\section{Patients and methods}

This was a prospective randomized comparative study performed at Brasília Ophthalmologic Hospital between August 2015 and January 2016. The study was approved by the institutional review board of University of São Paulo, Brazil. Enrolled patients were randomized into two groups: conventional phacoemulsification and FLACS. Preoperative evaluation consisted of biomicroscopy with cataract nucleus density classification in an unmasked manner by comparison with Lens Opacity Classification System (LOCS) III and the Pentacam ${ }^{\circledR}$ Nucleus Staging (PNS) software (Oculus Optikgerate $\mathrm{GmbH}$, Wetzlar, Germany). All surgeries were performed by the same surgeon (WTH) using the Centurion Vision System with Active Fluidics with the $0.9 \mathrm{~mm} 45^{\circ}$ ASP bypass system Intrepid Balanced Tip (Alcon Laboratories, Inc.), the $0.9 \mathrm{~mm}$ Intrepid Ultra Infusion Sleeve and $\mathrm{OZil}^{\circledR}$ Handpiece (Alcon Laboratories, Inc.), with the same ultrasound and fluidics configuration: continuous linear torsional, minimum $=10 \%$ and maximum $=100 \%$; longitudinal power $=0$; vacuum linear, minimum $=70 \mathrm{mmHg}$ and maximum $=350 \mathrm{mmHg}$; irrigation $\mathrm{IOP}=60 \mathrm{mmHg}$; ASP rate $=35 \mathrm{cc} / \mathrm{min}$; dynamic rise $=0$ and OZil IP settings of $95 \%$ vacuum threshold, torsional-longitudinal ratio of 1.0 and longitudinal pulse of $20 \mathrm{~ms}$. The OZil Intelligent Phaco IP software (Alcon Laboratories, Inc, Fort Worth, TX, USA) is a dynamically adaptive intelligent energy management system that continuously monitors and responds with a longitudinal ultrasound (Intelligent Phaco IP) to ongoing phacoemulsification conditions throughout the procedure, reduces occlusion and keeps the lens material flow to and through the tip. In our study, parameter longitudinal time is exceptionally for Intelligent Phaco IP.

All FLACSs were performed with LenSx ${ }^{\circledR}$ (Alcon Laboratories, Inc.) using the same parameters for nucleus treatment: one $6.0 \mathrm{~mm}$ diameter cylinder with fragment pattern, $12 \mu \mathrm{J}$ of laser energy, spot and layer separation of $20 \mu \mathrm{m}$ and fragment size of $400 \mu \mathrm{m}$. Clear corneal main incision was performed in the steepest axis of the cornea, and arcuate limbal relaxing incisions were realized following standard protocol. ${ }^{22}$ Laser capsulotomy had a $4.9 \mathrm{~mm}$ diameter. The karate prechop technique was used for all manual cases.

All eligible patients provided written informed consent, aged between 59 and 80 years, and had a diagnosis of cataract and planned phacoemulsification for one or both eyes. The key exclusion criteria included presence of white cataracts, need for mechanical dilation of pupil, weak or broken zonular fibers, known zonular instability or zonular dehiscence.

The main outcome measures were cumulative dissipated energy (CDE), torsional time (s), longitudinal time (s) (Intelligent Phaco IP), case time (s), fluid usage (s) and ASP time (s), as provided by the display on the user interface at the end of phacoemulsification. Measures were taken from the beginning of the surgery until the end of complete nucleus removal. Preoperative and postoperative (at 1 month) endothelial cell counts were measured using Nidek ${ }^{\circledR}$ CEM-530. ${ }^{11}$ The CDE is a built-in device of the Alcon Laboratories, Inc. It is an estimation of the ultrasound energy expended during the lens removal in a phacoemulsification cataract surgery. CDE information was determined using the formula: US power average $\times$ US time + torsional amplitude average $\times$ torsional US time $\times 0.4$ measured in percent-seconds (\%-s).

Collected data were submitted for statistical analysis using SPSS for Windows. Demographics data, safety outcomes and preoperative characteristics were summarized descriptively. Key outcomes were compared using covariance analysis with a significance level $(P)$ of 0.05 . 
Table I Age, LOCS III and PNS between FLACS and conventional surgery using Centurion Vision System with Active Fluidics Phaco Platform

\begin{tabular}{llllll}
\hline & FLACS & & \multicolumn{2}{l}{ Conventional } & $P$-value \\
\cline { 2 - 2 } & Average \pm SD & & Average \pm SD & \\
\hline Age & $67.9 \pm 8.7$ & & $69.1 \pm 8.9$ & $0.193-\mathrm{ns}$ \\
LOCS III & $2.02 \pm 0.44$ & & $1.98 \pm 0.72$ & $0.061-\mathrm{ns}$ \\
PNS & $1.60 \pm 0.80$ & & $1.52 \pm 0.92$ & $0.371-\mathrm{ns}$ \\
\hline
\end{tabular}

Abbreviations: LOCS, Lens Opacity Classification System; PNS, Pentacam ${ }^{\circledR}$ Nucleus Staging; FLACS, femtosecond laser-assisted cataract surgery; ns, not significant.

\section{Results}

Cataract surgery removal was performed in 400 eyes, 200 in each group (conventional surgery vs FLACS). There were no intraoperative complications.

There were no significant differences in age and cataract density classification between the groups (Table 1).

FLACS group showed significantly less CDE and torsional time (Figures 1 and 2).

Use of balanced salt solution (BSS), total case time, ASP time and longitudinal time (Intelligent Phaco IP) were significantly lower on the conventional group (Figures 3 and 4).

Endothelial cell loss was not significantly different between groups.

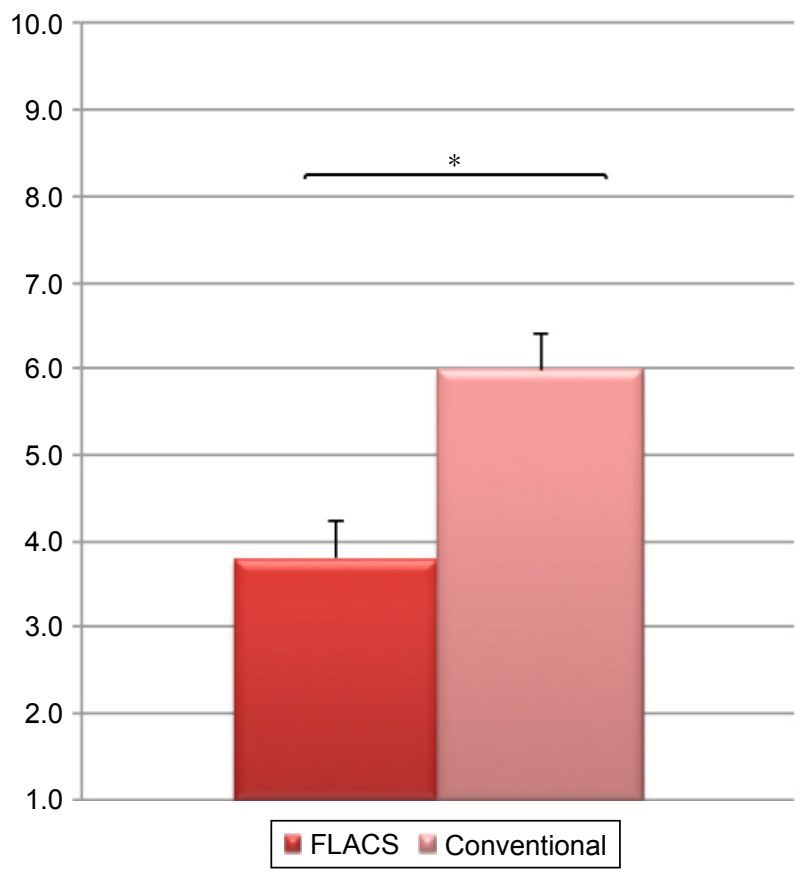

Figure I Comparison of CDE between FLACS and conventional surgery using Centurion Vision System with Active Fluidics Phaco Platform.

Notes: $P$-value is from a paired $t$-test. $* P<0.0001$

Abbreviations: CDE, cumulative dissipated energy; FLACS, femtosecond laserassisted cataract surgery.

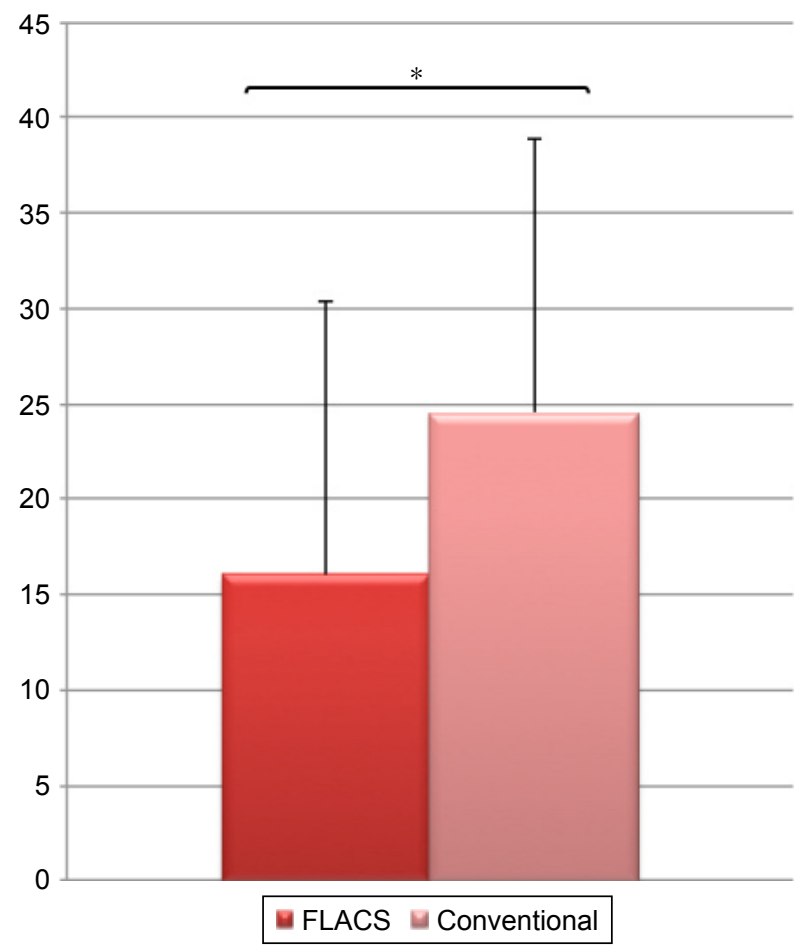

Figure 2 Comparison of torsional time (s) between FLACS and conventional surgery using Centurion Vision System with Active Fluidics Phaco Platform.

Notes: $P$-value is from a paired $t$-test. ${ }^{*} P<0.0001$.

Abbreviation: FLACS, femtosecond laser-assisted cataract surgery.

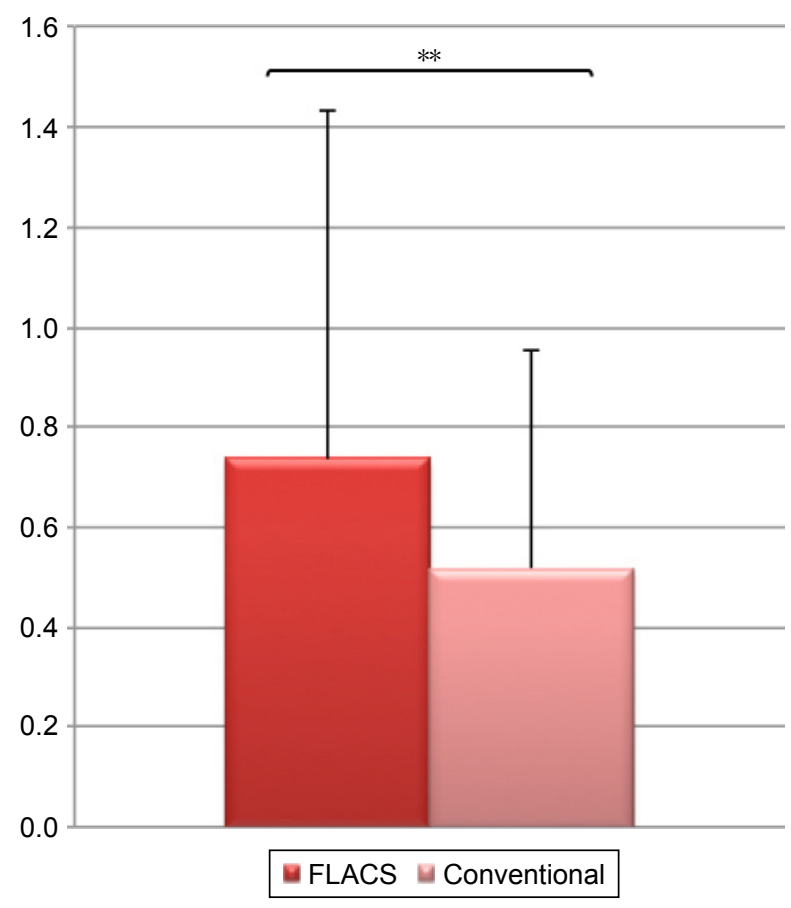

Figure 3 Comparison of phacoemulsification time (s) between FLACS and conventional surgery using Centurion Vision System with Active Fluidics Phaco Platform.

Notes: $P$-value is from a paired $t$-test. ${ }^{* *} P=0.0138$.

Abbreviation: FLACS, femtosecond laser-assisted cataract surgery. 


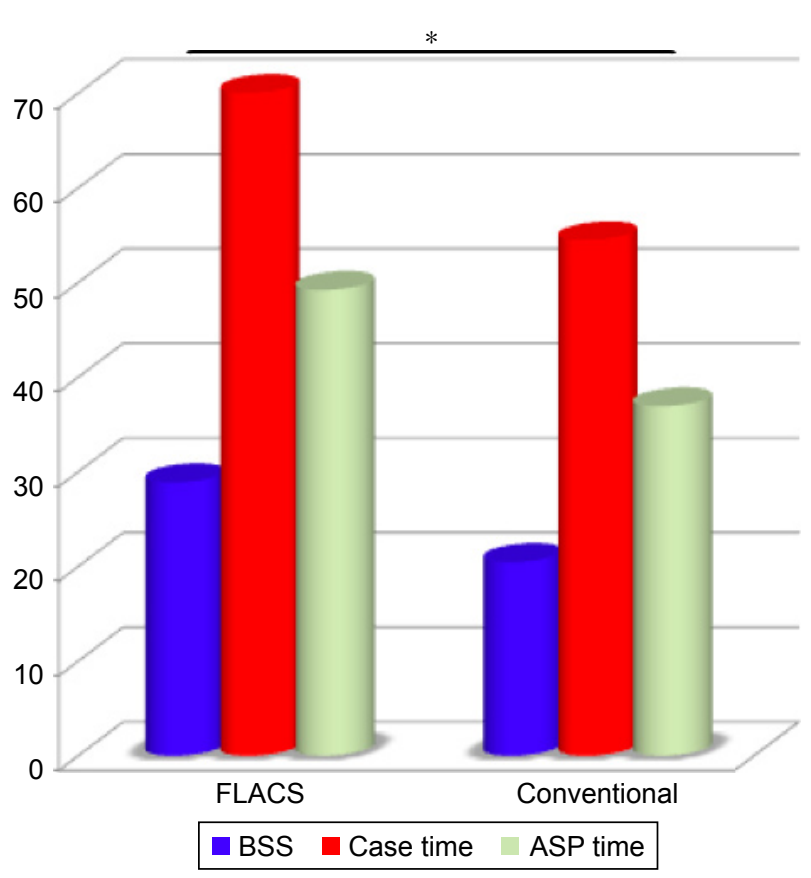

Figure 4 Comparison of fluid usage (BSS), case time (s) and ASP time (s) between FLACS and conventional surgery using Centurion Vision System with Active Fluidics Phaco Platform.

Notes: $P$-value is from a paired $t$-test. $* P<0.0001$.

Abbreviations: BSS, balanced salt solution; ASP, aspiration; FLACS, femtosecond laser-assisted cataract surgery.

\section{Discussion}

Presently, few published literatures comparing FLACS versus manual phacoemulsification regarding surgical outcomes exists. Many of the studies found in the literature were performed gathering data from different surgeons with no reference for surgical parameters or phacoemulsification machines, which are important factors for bias. ${ }^{14,20,23-25}$

To our knowledge, this is the first study that compared FLACS versus conventional phacoemulsification with a single surgeon and used exclusively the Centurion Active Fluidics System.

In recent years, FLACS has become more popular among ophthalmologists. The femtosecond laser has been introduced into phacoemulsification cataract surgery to effectively perform a bladeless arcuate and corneal incisions, capsulotomy and nuclear fragmentation. Numerous clinical studies have reported advantages of FLACS as reduced ultrasound energy, corneal endothelial cell damage and cornea edema. ${ }^{14-18}$

The importance of the single surgeon case series comes from the existing learning curve for FLACS, as demonstrated in the literature. ${ }^{24}$ In our study, the surgeon had performed $\sim 2,500$ FLACS cases prior to the study; therefore, there are no learning curve implications.
Our data showed that FLACS can reduce CDE and torsional time in comparison to conventional surgery, which agrees with a recent publication. ${ }^{25}$ Data have shown that conventional surgery used almost twice $\mathrm{CDE}$ time and at least $50 \%$ more of torsional time than FLACS. The importance of less ultrasound energy use during the procedure is well established in the literature, reducing corneal edema and endothelial cell loss. ${ }^{26,27}$

The role of FLACS with respect to endothelial cell loss reduction is not yet fully comprehended. Abell et al showed that endothelial cell loss is lower in FLACS at 3 weeks postoperatively, but with no differences at 6 months. FLACS with zero effective phaco time and manually created corneal incisions had statistically significantly less endothelial cell loss at 6 months than FLACS in laser-automated corneal incisions group and conventional phacoemulsification group..$^{19,23}$ In our study, there was no statistically significant difference in the endothelial cell count between groups at 1 month and 3 months postoperatively, according to the previously mentioned studies. ${ }^{19,23}$

There was an increased use of longitudinal power (Intelligent Pulse IP) in the FLACS group. Although statistically significant, we believe that this difference is of no relevance for surgical outcomes since the mean IP time in both groups was less than $1 \mathrm{~s}$, while torsional time was responsible for $15 \mathrm{~s}$ in the FLACS group and $20 \mathrm{~s}$ in the conventional group with no difference in the endothelial cells.

Several studies ${ }^{19,20,23,25}$ recently described the customization of laser fragmentation patterns to the type and density of the cataract. We standardized lens-softening pattern to improve academic value to the study. The femtosecond laser has a variety of methods with laser fragmentation patterns for lens-softening process, indicating that less effective phacoemulsification time is needed to emulsify the lens, but shows a distinct result concerned to case time and BSS usage. ${ }^{25,28}$ Fluid volume (BSS), case time and ASP time were significantly higher in the FLACS group. This finding confronts published literature, where these parameters were not of statistical significance between groups. ${ }^{11}$

In summary, this study found that the use of new technologies modifies surgical efficiency in different degrees. Manual phacoemulsification performed by an experienced surgeon with good technology and appropriate fluidic settings provides similar surgical outcomes. Research into new technologies should benefit in improving the efficiency of various surgical approaches. Further studies should evaluate other phacoemulsification machines and laser parameters. 
What was known:

- FLACS is able to reduce ultrasound energy use in cataract surgery.

What this paper adds:

- With the Active Fluidics System, fluid usage, case time and total ASP time can be higher in FLACS than in manual phacoemulsification.

\section{Disclosure}

None of the authors has a financial or proprietary interest in any material or method mentioned. The authors have no affiliations with or involvement in any organization or entity with any financial interest or nonfinancial interest in the subject matter or materials discussed in this manuscript. The authors report no other conflicts of interest in this work.

\section{References}

1. Foster A, ed. Vision 2020: Thecataract challenge. Community Eye Health. 2000;13(34):17-19.

2. Han YK, Miller KM. Heat production: longitudinal versus torsional phacoemulsification. J Cataract Refract Surg. 2009;35(10):1799-1805.

3. Christakis PG, Braga-Mele RM. Intraoperative performance and postoperative outcome comparison of longitudinal, torsional, and transversal phacoemulsification machines. J Cataract Refract Surg. 2012;38(2): 234-241.

4. Sharif-Kashani P, Fanney D, Injev V. Comparison of occlusion break responses and vacuum rise times of phacoemulsification systems. BMC Ophthalmol. 2014;14:96.

5. Solomon KD, Lorente R, Fanney D, Cionni RJ. Clinical study using a new phacoemulsification system with surgical intraocular pressure control. J Cataract Refract Surg. 2016;42(4):542-549.

6. Nagy ZZ, Kránitz K, Takacs AI, Miháltz K, Kovács I, Knorz MC. Comparison of intraocular lens decentration parameters after femtosecond and manual capsulotomies. J Refract Surg. 2011;27(8):564-569.

7. Oshika T, Kawana K, Hiraoka T, Kaji Y, Kiuchi T. Ocular higher-order wavefront aberration caused by major tilting of intraocular lens. Am J Ophthalmol. 2005;140(4):744-746.

8. Sanders DR, Sarver EJ, Cooke DL. Accuracy and precision of a new system for measuring toric intraocular lens axis rotation. J Cataract Refract Surg. 2013;39(8):1190-1195.

9. Ale JB. Intraocular lens tilt and decentration: a concern for contemporary IOL designs. Nepal J Ophthalmol. 2011;3(1):68-77.

10. Sanders DR, Higginbotham RW, Opatowsky IE, Confino J. Hyperopic shift in refraction associated with implantation of the single-piece Collamer intraocular lens. J Cataract Refract Surg. 2006;32(12): 2110-2112.
11. Wallace RB 3rd. Capsulotomy diameter mark. J Cataract Refract Surg. 2003;29(10):1866-1868.

12. Norrby S. Sources of error in intraocular lens power calculation. J Cataract Refract Surg. 2008;34(3):368-376.

13. Kanellopoulos AJ, Asimellis G. Standard manual capsulorhexis/ ultrasound phacoemulsification compared to femtosecond laser-assisted capsulorhexis and lens fragmentation in clear cornea small incision cataract surgery. Eye Vis (Lond). 2016;3:20.

14. Abouzeid H, Ferrini W. Femtosecond-laser assisted cataract surgery: a review. Acta Ophthalmol. 2014;92(7):597-603.

15. Roberts TV, Lawless M, Chan CC, et al. Femtosecond laser cataract surgery: technology and clinical practice. Clin Experiment Ophthalmol. 2013;41(2):180-186.

16. Serrao S, Lombardo G, Ducoli P, Rosati M, Lombardo M. Evaluation of femtosecond laser clear corneal incision: an experimental study. J Refract Surg. 2013;29(6):418-424.

17. Day AC, Gartry DS, Maurino V, Allan BD, Stevens JD. Efficacy of anterior capsulotomy creation in femtosecond laser-assisted cataract surgery. J Cataract Refract Surg. 2014;40(12):2031-2034.

18. Sutton G, Bali SJ, Hodge C. Femtosecond cataract surgery: transitioning to laser cataract. Curr Opin Ophthalmol. 2013;24(1):3-8.

19. Abell RG, Kerr NM, Vote BJ. Toward zero effective phacoemulsification time using femtosecond laser pretreatment. Ophthalmology. 2013;120(5):942-948.

20. Mastropasqua L, Mattei PA, Toto L, et al. All laser cataract surgery compared to femtosecond laser phacoemulsification surgery: corneal trauma. Int Ophthalmol. 2016;37(3):475-482.

21. Bartlett JD, Miller KM. The economics of femtosecond laser-assisted cataract surgery. Curr Opin Ophthalmol. 2016;27(1):76-81.

22. Nichamin LD. Nomogram for limbal relaxing incisions. J Cataract Refract Surg. 2006;32(9):1408; author reply 1408.

23. Abell RG, Kerr NM, Howie AR, Mustaffa Kamal MAA, Allen PL, Vote BJ. Effect of femtosecond laser-assisted cataract surgery on the corneal endothelium. J Cataract Refract Surg. 2014;40(11): 1777-1783.

24. Bali SJ, Hodge C, Lawless M, Roberts TV, Sutton G. Early experience with the femtosecond laser for cataract surgery. Ophthalmology. 2012;119(5):891-899.

25. Conrad-Hengerer I, Hengerer FH, Schultz T, Dick HB. Effect of femtosecond laser fragmentation of the nucleus with different softening grid sizes on effective phaco time in cataract surgery. J Cataract Refract Surg. 2012;38(11):1888-1894.

26. Murano N, Ishizaki M, Sato S, Fukuda Y, Takahashi H. Corneal endothelial cell damage by free radicals associated with ultrasound oscillation. Arch Ophthalmol. 2008;126(6):816-821.

27. Park J, Yum HR, Kim MS, Harrison AR, Kim EC. Comparison of phaco-chop, divide-and-conquer, and stop-and-chop phaco techniques in microincision coaxial cataract surgery. J Cataract Refract Surg. 2013; 39(10):1463-1469.

28. Nagy ZZ, McAlinden C. Femtosecond laser cataract surgery. Eye Vis (Lond). 2015;2:11.
Clinical Ophthalmology

\section{Publish your work in this journal}

Clinical Ophthalmology is an international, peer-reviewed journal covering all subspecialties within ophthalmology. Key topics include: Optometry; Visual science; Pharmacology and drug therapy in eye diseases; Basic Sciences; Primary and Secondary eye care; Patient Safety and Quality of Care Improvements. This journal is indexed on Submit your manuscript here: http://www.dovepress.com/clinical-ophthalmology-journal

\section{Dovepress}

PubMed Central and CAS, and is the official journal of The Society of Clinical Ophthalmology (SCO). The manuscript management system is completely online and includes a very quick and fair peer-review system, which is all easy to use. Visit http://www.dovepress.com/ testimonials.php to read real quotes from published authors. 